\title{
Plasma Levels of Vitamin E and Carotenoids are Decreased in Patients with Nonalcoholic Steatohepatitis (NASH)
}

\author{
A. Erhardt ${ }^{1}$, W. Stahl², H. Sies ${ }^{2}$, F. Lirussi ${ }^{3}$, A. Donner ${ }^{4}$, D. Häussinger ${ }^{1}$ \\ ${ }^{1}$ Clinic of Gastroenterology, Hepatology and Infectious Diseases, Heinrich-Heine-Universität, Düsseldorf, Germany \\ 2Institute of Biochemistry and Molecular Biology I, Heinrich-Heine-Universität, Düsseldorf, Germany \\ ${ }^{3}$ Department of Medical and Surgical Sciences, Universita degli Studi di Padova, Padova, Italy \\ ${ }^{4}$ Institute of Pathology, Rheinisch-Westfälisch-Technische-Universität, Aachen, Germany
}

\begin{abstract}
Objectives: Oxidative stress is suggested to play an important role in the pathogenesis of nonalcoholic steatohepatitis (NASH). The present study was aimed to compare plasma levels of antioxidants in patients suffering from NASH and healthy controls.

Methods: Plasma levels of the antioxidants $\alpha$-tocopherol, $\gamma$-tocopherol, lutein, zeaxanthin, $\beta$-cryptoxanthin, lycopene, $\alpha$-carotene $\beta$-carotene were determined in 57 patients with biopsy-proven NASH and 40 healthy controls.

Results: Levels of $\alpha$-tocopherol (22.4 vs. $26.8 \mathrm{nmol} /$ $\mathrm{ml} ; \mathrm{p}<0.01)$, lutein (0.19 vs. $0.33 \mathrm{nmol} / \mathrm{ml} ; \mathrm{p}<0.0001)$, zeaxanthin $(0.04$ vs. $0.08 \mathrm{nmol} / \mathrm{ml} ; \mathrm{p}<0.0001)$, lycopene $(0.15$ vs. $0.42 \mathrm{nmol} / \mathrm{ml} ; \mathrm{p}<0.0001), \alpha$-carotene $(0.03$ vs. $0.06 \mathrm{nmol} / \mathrm{ml} ; \mathrm{p}<0.005)$ and $\beta$-carotene $(0.25$ vs. $0.39 \mathrm{nmol} / \mathrm{ml} ; \mathrm{p}<0.01)$ were significantly decreased in NASH patients compared to controls. Age, aminotransferase status (ALT, AST) and BMI were not correlated with the levels of tocopherols or carotenoids.

Conclusions: Given the decreased levels supplementation of lipophilic antioxidants might be a rational treatment option for patients with NASH.
\end{abstract}

Key words: NASH - antioxidants - vitamin A - vitamin $\mathrm{E}$

\section{INTRODUCTION}

Nonalcoholic steatohepatitis (NASH) is a disease with a prevalence of $3-6 \%$ in the general population and up to $50 \%$ among patients with obesity [1]. NASH may progress to cirrhosis in a substantial number of patients. Due to the lack of an established treatment there is an increasing need for better understanding the pathogenesis of NASH in order to develop effective treatment options.

Insulin resistance and oxidative stress have been suggested to be major factors for the development of steatosis and progression to steatohepatitis [1]. In the processes of fatty acid oxidation and oxidative phosphorylation, peroxisomes and mitochondria leak reactive oxygen species (ROS) damaging biologically important molecules and cellular structures [1]. Due to its metabolic activity, the liver is exposed to a high load of pro-oxidants which are scavenged by an an- tioxidant network including dietary antioxidants. Supplementation of antioxidants was therefore proposed to counteract elevated ROS levels due to increased production and impaired inactivation. Among the promising antioxidant compounds are several micronutrients including tocopherols and carotenoids $[2,3]$.

Despite the theoretical and practical rationale for a supplementation with lipophilic antioxidants, levels of tocopherols and carotenoids and have not been systemically analyzed in patients with NASH. Decreased levels of antioxidants have been described in other liver diseases like alcoholic hepatitis, chronic hepatitis C, hemochromatosis and Wilson`s disease [4]. The present study was aimed to compare plasma levels of tocopherols and carotenoids in patients suffering from NASH and healthy controls.

\section{Patients, Methods and Statistics}

Fifty seven consecutive patients with biopsy-proven NASH were included in the study. Seven of the $57 \mathrm{pa-}$ tients took vitamin $\mathrm{E}$ or multivitamin supplements at the time of blood sampling and were assessed seperately. Exclusion criteria were other concomitant liver diseases, alcohol consumption $>20 \mathrm{~g} /$ day or a cholesterol level $>350 \mathrm{mg} / \mathrm{dl}$. Forty healthy employees served as controls. The study has been approved by the local ethical committee and all subjects gave informed consent to the work. NASH was histologically assessed according to Brunt et al. [5]. Liver biopsy was obtained at no more than 12 months apart from blood sampling. Plasma levels of $\alpha$-tocopherol, $\gamma$-tocopherol, retinol, lutein, zeaxanthin, $\beta$-cryptoxanthin, lycopene, $\alpha$-carotene and $\beta$-carotene were determined by means of HPLC following an established protocol [6]. Statistics: Two sided t-test and descriptive statistics were used to weight analyses for means with the SPSS 18.0 statistical software. Significance was set at the $\mathrm{p}<0.05$ level.

\section{RESULTS}

Clinical and laboratory data are summarized in Table 1. $\alpha$-Tocopherol, lutein, lycopene, $\alpha$ - and $\beta$-carotene were significantly decreased in NASH patients compared to healthy controls: plasma levels of $\alpha$-tocopherol were lowered by $16 \%$ and levels of carotenoids 
Table 1. Baseline characteristics of healthy controls $(\mathrm{n}=40)$ and patients with NASH without $(\mathrm{n}=50)$ and with vitamin supplementation ( $\mathrm{n}=7$ ).

\begin{tabular}{|c|c|c|c|c|c|}
\hline & $\begin{array}{l}\text { Healthy } \\
\text { controls } \\
(\mathrm{n}=40)\end{array}$ & $\begin{array}{l}\text { NASH } \\
(\mathrm{n}=50)\end{array}$ & $\begin{array}{l}\text { P value } \\
\text { (different } \\
\text { from control) }\end{array}$ & $\begin{array}{l}\text { NASH } \\
+ \text { vitamin } \\
\text { supplements } \\
(\mathrm{n}=7)\end{array}$ & $\begin{array}{l}\text { P-value } \\
\text { (different } \\
\text { from NASH) }\end{array}$ \\
\hline$\alpha$-Tocopherol $[\mathrm{nmol} / \mathrm{ml}]$ & $26.8 \pm 7.9$ & $22.4 \pm 8.1$ & 0.01 & $39.6 \pm 1.5$ & 0.0001 \\
\hline$\gamma$-Tocopherol $[\mathrm{nmol} / \mathrm{ml}]$ & $2.5 \pm 0.8$ & $2.5 \pm 0.9$ & n.s. & $3.0 \pm 1.0$ & n.s. \\
\hline Retinol $[\mathrm{nmol} / \mathrm{ml}]$ & $1.5 \pm 1.9$ & $1.2 \pm 0.5$ & n.s. & $1.3 \pm 0.4$ & n.s. \\
\hline Lutein $[\mathrm{nmol} / \mathrm{ml}]$ & $0.33 \pm 0.11$ & $0.19 \pm 0.09$ & 0.0001 & $0.26 \pm 0.17$ & n.s. \\
\hline Zeaxanthin $[\mathrm{nmol} / \mathrm{ml}]$ & $0.08 \pm 0.03$ & $0.04 \pm 0.01$ & 0.0001 & $0.045 \pm 0.03$ & n.s. \\
\hline Cryptoxanthin $[\mathrm{nmol} / \mathrm{ml}]$ & $0.13 \pm 0.07$ & $0.09 \pm 0.09$ & n.s. $(0.06)$ & $0.12 \pm 0.06$ & n.s. \\
\hline Lycopene $[\mathrm{nmol} / \mathrm{ml}]$ & $0.42 \pm 0.24$ & $0.15 \pm 0.16$ & 0.001 & $0.50 \pm 0.37$ & n.s. $(0.07)$ \\
\hline$\alpha$-Carotene $[\mathrm{nmol} / \mathrm{ml}]$ & $0.06 \pm 0.05$ & $0.03 \pm 0.03$ & 0.005 & $0.07 \pm 0.09$ & n.s. \\
\hline$\beta$-Carotene $[\mathrm{nmol} / \mathrm{ml}]$ & $0.39 \pm 0.26$ & $0.25 \pm 0.26$ & 0.01 & $0.42 \pm 0.27$ & 0.03 \\
\hline Ferritin $[\mu \mathrm{g} / 1]$ & $96 \pm 73$ & $237 \pm 293$ & 0.007 & $103 \pm 99$ & n.s. \\
\hline TS $[\%]$ & $31 \pm 13$ & $34 \pm 13$ & n.s. & $34 \pm 11$ & n.s. \\
\hline Age [years] & $50 \pm 15$ & $51 \pm 16$ & n.s. & $49 \pm 10$ & n.s. \\
\hline Gender $[\%$ males $]$ & 54 & 55 & n.s. & 57 & n.s. \\
\hline
\end{tabular}

Abbr.: $\mathrm{TS}=$ transferrin saturation

by 31-64\%. Patients with NASH displayed higher serum levels of ferritin but similar transferrrin saturation compared to healthy controls. NASH patients using vitamin supplements had higher $\alpha$-tocopherol and $\beta$-carotene levels than those which did not apply additional vitamins (Table 1). BMI, ALT, AST, GGT and cholesterol levels were not correlated to the levels of tocopherols or carotenoids. HbA1c was significantly correlated to ferritin $(r=0.439 ; \mathrm{p}<0.002)$ but not to the levels of carotenes or tocopherols. Age showed a moderate correlation to $\alpha$-tocopherol ( $\mathrm{r}=0.395$; $\mathrm{p}<0.05)$ but not to $\gamma$-tocopherol or carotenes. There was a weak inverse correlation of $\gamma$-tocopherol to the grade of inflammation $(\mathrm{r}=-0,545 ; \mathrm{p}<0.07)$ and stage of fibrosis $(\mathrm{r}=-0.388 ; \mathrm{p}<0.01)$.

\section{Discussion}

The present study demonstrates that dietary antioxidant compounds are significantly decreased in patients with NASH compared to healthy controls. The reasons for this observation might be a depletion of antioxidants in order to counterbalance oxidative stress. Low levels of antioxidants might also be caused by a reduced oral uptake. The present finding of decreased antioxidants in patients with NASH could argue in favour of an antioxidant treatment strategy.

However, data on the supplementation with antioxidants in NASH are not conclusive and based only on small trials. Most studies investigated vitamin E substitution but no prospective study regarding treatment with carotenoids has been launched. In a pilot study with 11 children with NASH, elevated blood aminotransferases activity was decreased upon vitamin $\mathrm{E}$ in- tervention [7] and in a small randomized controlled trial the combination of ursodeoxycholic acid with vitamin E improved ALT levels as well as the inflammatory activity in the liver. A therapy of vitamins $\mathrm{E}$ and $\mathrm{C}$ for 6 months improved liver fibrosis in 45 patients in a placebo-controlled trial [2] but had no effect on transaminases and necroinflamatory activity. A 12 week therapy with vitamin $\mathrm{E}$ in 16 adults provided no additional benefit to that obtained by lifestyle modifications [8], whereas a longer treatment of 12 months showed improvements in inflammation and fibrosis in a small, nonrandomized study [9]. Discrepancies in the studies might derive from the use of different vitamin E compounds, dosages and treatment durations. The term vitamin E summarizes structurally different tocopherols and tocotrienols, four of each group, which naturally occur as only one optical isomer [10]. Synthetic vitamin $\mathrm{E}$, mainly $\alpha$-tocopherol, usually occurs as a mixture of various optical isomers. RRR- $\alpha$-tocopherol is the biologically most active vitamin and is selected in the liver by the $\alpha$-tocopherol-transfer-protein $(\alpha$-TTP). Differences in the vitamin pattern of the supplements may explain the divergent results of the intervention studies. Furthermore, tocopherols and carotenoids exert additional non-oxidative functions like immuno-modulation, regulation of cell cycle and induction of detoxifying enzymes involved in mechanisms of cell protection [10]. However the so far largest and most recent randomized, double-blind, placebo-controlled trial of 247 patients who had $\mathrm{NASH}$ but not diabetes showed that vitamin E given as RRR- $\alpha$-tocopherol at a dose $800 \mathrm{IU} /$ day for 96 weeks improved key histological features and liver enzymes [11]. 
Lycopene is a predominant carotenoid in human plasma and considered to be a potent antioxidant and a singlet oxygen quencher [12]. There is increasing evidence in support for a protective role of lycopene in a variety of human diseases with increased oxidative stress including cancers, cardiovascular disorders, osteoporosis and male infertility [12]. Lycopene was significantly reduced in NASH patients of the present study. So far there are no randomized studies that have investigated the role of lycopene in patients with NASH. However, the possibility for an easy dietary supplementation makes lycopene an interesting candidate for the treatment of NASH.

In conclusion, the observed decrease of tocopherol and carotenoid levels implies that oxidative stress plays a role in the pathogenesis of NASH. The present data support the study by Sanyal et al. that antioxidant supplementation might be a rational treatment option for patients with NASH. However, delineation of treatment strategies in NASH will have to take into account suitable treatment durations and clinical endpoints, the use of naturally occuring tocopherols and the risk of pro-oxidative effects of some carotenoids.

Acknowledgements: The authors thank A. Homssi for technical support during the study.

\section{REFERENCES}

1. Angulo P. Nonalcoholic fatty liver disease. $\mathrm{N}$ Engl J Med. 2002 Apr 18;346(16):1221-31.

2. Harrison SA, Torgerson S, Hayashi P, Ward J, Schenker $\mathrm{S}$. Vitamin $\mathrm{E}$ and vitamin $\mathrm{C}$ treatment improves fibrosis in patients with nonalcoholic steatohepatitis. Am J Gastroenterol. 2003 Nov;98(11):2485-90.

3. Dufour JF, Oneta CM, Gonvers JJ, Bihl F, Cerny A, Cereda JM, et al. Randomized placebo-controlled trial of ursodeoxycholic acid with vitamin $\mathrm{E}$ in nonalcoholic steatohepatitis. Clin Gastroenterol Hepatol. 2006 Dec; 4(12):1537-43.

4. von Herbay A, de Groot H, Hegi U, Stremmel W, Strohmeyer G, Sies H. Low vitamin E content in plasma of patients with alcoholic liver disease, hemochromatosis and Wilson's disease. J Hepatol. 1994 Jan;20(1):41-6.
5. Brunt EM, Janney CG, Di Bisceglie AM, NeuschwanderTetri BA, Bacon BR. Nonalcoholic steatohepatitis: a proposal for grading and staging the histological lesions. Am J Gastroenterol. 1999 Sep;94(9):2467-74.

6. Aust O, Sies H, Stahl W, Polidori MC. Analysis of lipophilic antioxidants in human serum and tissues: tocopherols and carotenoids. J Chromatography. 2001 Nov 30; 936(1-2):83-93.

7. Lavine JE. Vitamin E treatment of nonalcoholic steatohepatitis in children: a pilot study. J Pediatr. 2000 Jun; 136(6):734-8.

8. Kugelmas M, Hill DB, Vivian B, Marsano L, McClain CJ. Cytokines and NASH: a pilot study of the effects of lifestyle modification and vitamin E. Hepatology. 2003 Aug;38(2):413-9.

9. Hasegawa T, Yoneda M, Nakamura K, Makino I, Terano A. Plasma transforming growth factor-beta1 level and efficacy of alpha-tocopherol in patients with non-alcoholic steatohepatitis: a pilot study. Alimentary Pharmacology \& Therapeutics. 2001 Oct;15(10):1667-72.

10. Sies H, Stahl W. Vitamins E and C, beta-carotene, and other carotenoids as antioxidants. The American Journal of Clinical Nutrition. 1995 Dec;62(6 Suppl):1315S-21S.

11. Sanyal AJ, Chalasani N, Kowdley KV, McCullough A, Diehl AM, Bass NM, et al. Pioglitazone, vitamin E, or placebo for nonalcoholic steatohepatitis. N Engl J Med. 2010 May 6;362(18):1675-85.

12. Rao AV, Rao LG. Carotenoids and human health. Pharmacol Res. 2007 Mar;55(3):207-16.

Received: December 20, 2010 / Accepted: January 20, 2011

Address for correspondence:

Prof. Dr. med. Andreas Erhardt

Klinik für Gastroenterologie, Hepatologie und Infektiologie

Heinrich-Heine-Universität Düsseldorf

Moorenstr. 5

40225 Düsseldorf

Germany

Tel.: $\quad+49-211-8118268$

Fax: +49-211-8118132

E-mail: erhardt@med.uni-duesseldorf.de 